\title{
La ordenación del turismo y sus relaciones con la legislación de ordenación del territorio, del urbanismo y de la protección del medio ambiente*
}

\author{
Javier Sola Teyssiere \\ Catedrático de Escuela Universitaria de Derecho Administrativo \\ Universidad de Sevilla
}

\begin{abstract}
SUMARIO : I. LA ORDENACIÓN DEL TURISMO. 1. Los distintos objetos de la ordenación del turismo. 2. La problemática de la ordenación del turismo en su vertiente espacial. 3. Principios de la ordenación espacial turística.- II. ENLACE CON LA ORDENACIÓN DEL TERRITORIO. 1. Protagonismo competencial autonómico. 2. El instrumento de actuación: la planificación. 3. La planificación turística en el marco de la planificación territorial: el estado de la cuestión en las distintas Comunidades Autónomas. 4. Especial referencia a la situación de Andalucía.- III. RELACIO NES CON LA LEGISLACIÓN URBANÍSTICA. 1. Incidencia de la normativa urbanística sobre la ordenación de la urbanización turística. 2. Disposiciones de naturaleza urbanística establecidas desde la legislación sectorial turística.-IV. RELACIONES CON LA LEGISLACIÓN DE PROTECCIÓN DEL MEDIO AMBIENTE. 1. El contexto condicionante de la normativa medioambiental. 2. La normativa sobre espacios natural es protegidos. 3. La sujeción a evaluación de impacto ambiental de determinados proyectos relativos a actuaciones turísticas. 4. La sujeción de las instalaciones turísticas a otras normativas en materia de protección medioambiental.
\end{abstract}

\section{LA ORDENACIÓN DEL TURISMO}

Conforme al carácter claramente introductorio de esta ponencia, nos parece conveniente dedicar la primera parte de la misma a reflexionar sobre el

\footnotetext{
* El presente trabajo recoge el texto de la Ponencia desarrollada por el autor en las Jornadas sobre T urismo y Ordenación Territorial, celebradas en Sevilla, en la sede de la Consejería de Turismo y Deporte, durante los días 2 y 3 de marzo de 2004, al que se han añadido unas mínimas notas bibliográficas ineludibles.
} 
alcance de la expresión que da comienzo a su título: "la ordenación del turismo". ¿Qué abarca realmente la ordenación del turismo?. Tratemos de responder a esta cuestión sin ánimo de exhaustividad, sino más bien en el ánimo de acotar nuestro tema -que es el de la vertiente espacial de dicha ordenación-, con objeto de situarnos en una adecuada posición de partida.

\section{Los distintos objetos de la ordenación del turismo}

\section{a. Los servicios turísticos}

El Derecho, tradicionalmente, se ha ocupado de la ordenación jurídica de las actividades económicas consideradas propiamente turísticas, es decir de aquellos servicios prestados al usuario bajo contraprestación como pueden ser los de alojamiento, de restauración, de intermediación y otras actividades relacionadas con el ocio. Y ello se ha llevado a cabo -sin entrar aquí en las técnicas de fomento- siguiendo el esquema clásico de la intervención jurídicopública de limitación o que los juristas denominamos de "policía administrativa". Esto es, si tomamos como ejemplo la actividad hotelera, mediante el establecimiento de una reglamentación estricta de los requisitos iniciales exigibles para la autorización de apertura del establecimiento, también de los deberes y obligaciones a observar por los empresarios en el posterior ejercicio de la actividad; lo que se ve acompañado por el despliegue de una actividad administrativa de control e inspección y, en su caso, sancionadora, por parte de las Administraciones competentes. Todo ello con una finalidad tuitiva de los derechos del usuario reconocidos a nivel constitucional (art. 51).

\section{b. El componente "ambiente" del destino turístico}

Pero, más recientemente, se ha sentido la necesidad de atender a otras cuestiones en la ordenación del turismo, pues la oferta turística presenta un segundo componente relativo al "ambiente" donde se desenvielve la estancia o la "experiencia turística", teniendo en cuenta que el turista, con frecuencia, no se desplaza a un determinado lugar sólo por la calidad de unas instalaciones concretas sino que entre sus motivaciones cuenta el atractivo del contexto donde éstas se incardinan.

Este segundo componente de lo que podríamos calificar como "producto turístico", considerado en su globalidad, aparece integrado por elementos absolutamente heterogéneos ${ }^{1}$, entre los que, a su vez, podríamos distinguir:

${ }^{1}$ Cfr. LÓ PEZ OLIVARES, D., La ordenación y planificación integrada de los recursos territoriales turísticos, Castellón de la Plana, 1998, pág. 31. Vid. también BARRADO TIMÓ N, D. A., Ordenación te 
$a^{\prime}$. Por un lado, una serie de aspectos, responsabilidad de las Administraciones públicas, que deben de ser atendidos a través de la técnica del servicio público, como pueden ser la seguridad ciudadana, la limpieza viaria, los transportes, el horario de los museos, los servicios de información, etc.

$b^{\prime}$. De otro lado, otra serie de factores de índole estructural, como son los relativos a:

- la correcta conservación del entorno, ya sea natural o urbano, del destino;

- la suficiencia de las infraestructuras viarias y para la prestación de suministros;

- y, a un nivel espacial más reducido, la adecuada configuración de los espacios de estancia del turista; esto es, de la urbanización y de las edificaciones al servicio de las actividades turísticas.

Es verdaderamente relevante destacar que la experiencia global que los turistas obtienen, no sólo de los servicios turísticos contratados, sino, junto a ello, de todo el conglomerado de elementos descrito ${ }^{2}$, es lo que determina el nivel de satisfacción de los mismosy, por ende, el éxito o decadencia de un determinado destino turístico.

En línea con la bipolaridad señalada, las modernas regulaciones del sector mantienen como focos principales de atención ${ }^{3}$ : a) de un lado, las actividades propias de los empresarios turísticos y, frente a ellas, la posición del usuario; b) de otro, los diversos elementos que componen los "escenarios" en que se desarrollan dichas actividades, esto es, los que a nivel doctrinal y normativo, vienen designándose como recursos turísticos ${ }^{4}$, caracterizados por cons-

rritorial y desarrollo turístico. Posibilidades, model os y esquemas de ordenación territorial del turismo en la España de las Autonomías, Rev. «Estudios Turísticos», no 149, 2001, pág. 5.

${ }^{2}$ Cfr. BOU LLÓN, R. C., Planificación de espacio turístico, Ed. Trillas, 3ª ed. (2ª reimp.), México, 2001, pág. 95. También BARRADO TIMÓN, D. A., Ordenación territorial y desarrollo turístico..., cit., pág. 5.

${ }^{3}$ Cfr. BLANQUER CRIADO, D., Derecho del Turismo, Valencia, 1999, pág. 22; para quien, además de las actividades y bienes a las que se alude en el texto, el Derecho del Turismo se refiere a unos determinados sujetos (el turista, el empresario y la Administración Pública).

${ }^{4}$ Concepto que ha sido estudiado detenidamente por J. TUDELA ARANDA, El significado jurídico y función de los recursos turísticos en la nueva legislación turística, en ob. col. Régimen jurídico de los recursos turísticos, (ed. J. Tudela Aranda), Zaragoza, 1999, págs. 201 ss. 
tituir bienes con capacidad de atracción o generación de flujos turísticos.

En la mayoría de los casos se trata de bienes puestos a disposición de los turistas y de los ciudadanos en general de forma gratuita -ya que se financian con cargo a los presupuestos públicos- y cuya gestión corresponde a los poderes públicos. Desde el punto de vista jurídico, la protección de muchos de estos recursos encuentra debida justificación en diversos principios enunciados constitucionalmente, como son los de protección de los recursos naturales, del medio ambiente, del patrimonio histórico o de los bienes de dominio público. De manera añadida, dicha protección no puede ser contemplada como algo "ajeno" a lo propiamente turístico desde el momento en que, frecuentemente, es la adecuada conservación de dichos recursos lo que posibilita que un destino sea atractivo para el desarrollo de esta actividad; por lo que dicha protección cobra así una dimensión e interés propiamente turísticos.

El tema objeto de estas Jornadas se incardina en el contexto de los factores de índole estructural a los que nos hemos referido, dada la estrecha interrelación entre turismo y territorio. Esto último constituye una evidencia en la que no parece necesario extenderse demasiado. Por una parte el territorio, el suelo, es un recurso esencial para el desarrollo de la actividad turística, necesario para el asentamiento de las instalaciones; y, a su vez, el turismo presenta una fuerte incidencia en la transformación del espacio físico, condicionando la organización del territorio ${ }^{5}$. De la misma manera a nadie se le escapa que se produce una afección mutua entre turismo y medio ambiente: así, a la vez que el entorno natural es un recurso turístico, el excesivo número de visitantes puede producir un impacto negativo sobre el mismo.

\section{La problemática de la ordenación del turismo en su vertiente espacial}

a. En sede municipal: la dinámica de expansión desmesurada

La ordenación del fenómeno turístico en su vertiente espacial plantea variados problemas, de entre los que destacaríamos, en este momento, uno principal.

Incurriendo en una indebida generalización, suele señalarse a las instan-

${ }^{5}$ Vid. al respecto BLANCO HERRANZ, F.J., Nuevas respuestas legislativas para la planificación te rritorial del turismo en España, Rev. «Papers de Turisme», nํ 27, 2000, pág. 48. 
cias municipales como a las responsables de un excesivo desarrollo urbanístico, especialmente en las zonas litorales, frecuentemente ligado, además, a un modelo turístico residencial. La problemática que, generalmente, se asocia a los desarrollos turísticos basados en este modelo aparece relacionada con el excesivo consumo de suelo, con el impacto negativo que genera en el medio natural, con la destrucción del paisaje, y también con el desbordamiento de la capacidad de carga del territorio, llevando a la consiguiente pérdida de atractivo de los valores originales del propio destino turístico. También se ha señalado, justamente, que este modelo de implantación aparece más ligado al negocio de la construcción y de la promoción inmobiliaria que al propiamente turístico. ${ }^{6}$

En este sentido, sin embargo, quizás no se ha resaltado lo suficiente que muchas de las actuaciones censuradas no sólo son ajenas sino frontalmente contrarias a los intereses del sector empresarial que gestiona la tipología de oferta quizás más relevante del negocio turístico. Esto es, la basada en la actividad de alojamiento, que es la que se muestra más capaz de generar a su alrededor todo un entramado de servicios complementarios de ocio, restauración, actividades recreativas o comerciales y que, en suma, es la que genera más riqueza y empleo.

No obstante, resulta relativamente fácil constatar que muchos Municipios costeros son proclives a una expansión desmesurada de sus suelos urbanos con un destino turístico, residencial o mixto, provocando una saturación insostenible. Esta falta de sensibilidad y visión territorial a largo plazo mostrada por ciertas Administraciones municipales - a veces acuciadas por otros problemas-, ha provocado una creciente intervención ordenadora de las instancias autonómicas en determinadas Comunidades, justificada, a la postre, por razones de mantenimiento del propio recurso, que constituye el principal activo del producto turístico.

b. En sede autonómica: los problemas de coordinación

Pero en sede autonómica nos encontramos, en ocasiones, con un segundo problema que está relacionado con la frecuente asignación de las competencias sobre tres de los elementos en juego -ordenación del territorio, medio

\footnotetext{
${ }^{6} \mathrm{Cfr}$. las consideraciones vertidas acerca de las cuestiones señaladas por VERA REBOLLO, J. F. e IVARS BAIDAL, J. A., Turismo, territorio y desarrollo regional en la Comunidad Valenciana, en ob. col. Ordenación y gestión del territorio turístico, (Dir. D. Blanquer Criado), Valencia, 2002, págs. 164 y 186.
} 
ambiente y turismo- a distintos Departamentos -en nuestro caso Consejeríasdentro de la Administración autonómica. Esta circunstancia origina no pocos conflictos y, a buen seguro, habrá de llevarnos a tratar a lo largo de estas Jornadas acerca de las técnicas de coordinación entre diferentes órganos dentro de la misma Administración.

\section{Principios de la ordenación espacial turística}

Sin perjuicio de ello, quisiéramos terminar esta primera parte de la exposición manifestando que el reto hoy planteado a los responsables públicos es el de encauzar los crecimientos turísticos bajo tres principios básicos. Los dos primeros están bien decantados y aparecen recogidos en muchos de los documentos de organismos internacionales relacionados con el tema, en la mayoría de los trabajos doctrinales y también en la mayor parte de las leyes autonómicas sobre turismo:

a) Por un lado, el principio de sostenibilidad, evitando, entre otras cosas, que se produzcan situaciones de sobresaturación que se vuelvan en contra del propio destino.

b) Por otro el de calidad, que ha de llevarnosa propiciar, por ejemplo, que se proyecten urbanizaciones y edificaciones turísticas dotadas de las prestaciones que demanda el turista actual y que generen mayor valor añadido; esto es, mayor rentabilidad por plaza.

c) Junto a ello, debería de atenderse, en nuestra opinión, a un tercer criterio, por lo general menos destacado, que guarda relación con las decisiones de afección de determinados suelos a los usos que se estimen socialmente más rentables, lo que conecta con la función social de la propiedad ex artículo 33.2 de la Constitución. En este sentido, parece que debiera optarse, como regla de principio, por aquellos modelos de oferta turística que se juzgaran más rentables desde el punto de vista del progreso social y económico y de la creación de empleo, principios rectores de la política social yeconómica enunciados en el artículo 40 de la Constitución.

En definitiva, dada pues la interacción entre territorio - turismo - medio ambiente, que no se puede soslayar, debe propugnarse la necesidad de llevar a cabo una articulación entre la normativa general sobre ordenación del territorio y el urbanismo, con la sectorial turística y con la medioambiental, estableciendo los correspondientes enlaces entre ellas. A partir de este momen- 
to, el objeto de esta ponencia, conforme a su título, se dirige a analizar si estos enlaces se vienen produciendo y en qué forma.

\section{ENLACE CON LA ORDENACIÓN DEL TERRITORIO}

Centrémonos, en primer lugar, en las relaciones con la legislación sobre ordenación del territorio.

\section{Protagonismo competencial autonómico}

Conviene aludir, aunque sea de pasada, al antecedente que en este sentido supuso la antigua L ey de Centros y Zonas de Interés T u rístico Nacional de 28 de diciembre de 1963, dictada en un momento caracterizado por la fuerte centralización de las competencias en la materia en la Administración del Estado; concretamente en el Ministerio de Información y Turismo.

En contraposición con dicha situación, precisamente conviene comenzar resaltando que el gran cambio experimentado en la configuración y orientación de la acción pública de ordenación espacial del turismo, tras la implantación del Estado constitucional, tiene mucho que ver con la conjunción en sede autonómica de la titularidad del núcleo de las competencias sobre ordenación del territorio y turismo, que otorga a las Comunidades Autónomas una amplia capacidad de disposición sobre la ordenación espacial del turismo en sus respectivos territorios, produciéndose, por ende, una regionalización de las competencias en esta materia.

\section{El instrumento de actuación: la planificación}

Sentado lo anterior, la siguiente cuestión estriba en localizar, de entre el elenco de potestades a disposición de las Administraciones Públicas, el instrumento más adecuado para llevar a cabo la función señalada, lo que nos lleva indefectiblemente hacia la técnica de la planificación, si se pretende que la ordenación de un determinado espacio pueda llegar a adquirir un valor relevante como producto turístico, como se ha señalado desde la OMT ${ }^{7}$. Como se advierte en el Plan Integral de Calidad del Turismo Español 2000-2006, «por lo que se refiere a los destinos turísticos, la falta de planificación, del conocimiento de los mercados y de visión a largo plazo pueden desembocar en una

7 Vid. ORGANIZACIÓN MUNDIAL DEL TURISMO, Introducción al Turismo, Madrid, 1998, pág. 179. 
situación de exceso de densidad, insuficiencia de infraestructuras o sobredimensionamiento de la oferta, que a su vez hace bajar la rentabilidad de las empresas con la consiguiente descapitalización de las mismas». 8

\section{a. Atributos de la planificación}

Dicha planificación debe contar además con dos atributos. En primer lugar, debe adoptar una óptica intersectorial y coordinada, dada la consideración compleja del fenómeno turístico y la necesidad de aunar los intereses propios de este sector con otros intereses en juego, como pueden ser los medioambientales, los comerciales o los relacionados con determinadas infraestructuras o transportes. En segundo lugar, la supraterritorialidad. Ha de resaltarse que la implantación de proyectos turísticos de cierta magnitud presenta una clara afección a infraestructuras y servicios que exceden, frecuentemente, del estricto interés de un solo municipio. De ahí la necesidad, de abordar los problemas derivados de estas implantaciones desde una perspectiva territorial supramunicipal ${ }^{9}$. Ciertamente, en el actual marco organizativo español, ello va a conllevar, el trasvase de buena parte de la toma de decisiones desde la instancia municipal a la autonómica, superponiéndose a aquélla.

\section{b. Los instrumentos de ordenación territorial}

Las consideraciones anteriores conducen a formular la conveniencia ${ }^{10}$, en bastantes ocasiones, de utilizar los instrumentos de ordenación del territorio como técnica de planificación capaz de ofrecer una respuesta integrada a los proteicos problemas que plantea la ordenación de los espacios turísticos y que, al adoptarse para un ámbito territorial más amplio que el municipal -regional 0 , preferentemente, comarcal-, permita superar las desviaciones que, en ocasiones, genera una gestión localista de los mismos. Evidentemente, la participación de la Administración turística en la elaboración de los instru-

\footnotetext{
8 MINISTERIO DE ECONOMÍA, Plan Integral deCalidad del Turismo Español 2000-2006, Madrid, 1999, pág. 25.

${ }^{9}$ Vid. al respecto, por todos, SOCÍAS CAMACHO, J. M., La incidencia del turismo en la ordenación del litoral (referencia especial al caso de las Islas Baleares), en ob. col. Régimen jurídico de los recursos turísticos, (ed. J. Tudela Aranda), Zaragoza, 1999, págs. 279-282.

${ }^{10}$ En este sentido RO GER FERNÁNDEZ, G., El urbanismo y la ordenación y gestión del territorio turístico, en ob. col. Ordenación y gestión del territorio turístico, (Dir. D. Blanquer Criado), Valencia, 2002, pág. 69.
} 
mentos aludidos parece esencial para que el resultado final aparezca convenientemente impregnado de la perspectiva sectorial que se pretende.

\section{La planificación turística en el marco de la planificación territorial: el esta- do de la cuestión en las distintas Comunidades Autónomas}

Veamos, seguidamente, cuáles son las previsiones que, a nivel normativo, han establecido las Comunidades Autónomas en este sentido.

Una de las principales novedades de las leyes turísticas autonómicas -dictadas entre 1994 y 2003- consiste en la previsión, en buena parte de ellas, de planes generales del turismo. No obstante, ha de advertirse de inmediato que la función asignada a dichos planes presenta perfiles materiales y jurídicos muy diversos. Ello es lógico, teniendo en cuenta que no todas las Comunidades Autónomas presentan las mismas necesidades de planificación turística territorial, dependiendo de las circunstancias singulares de su propio territorio, del desarrollo turístico adquirido y de otros factores.

Pues bien, atendiendo simultáneamente al dato objetivo del tipo de Planes configurados por las L eyes turísticas y al criterio de la conexión prevista -o la falta de la misma- de cada plan con los instrumentos de ordenación territorial instaurados en cada Comunidad Autónoma, se pueden distinguir, a efectos sistemáticos, cuatro modelos ${ }^{11}$ :

A) Un primer grupo de leyes autonómicas sobre ordenación del turismo que no han previsto un plan de turismo de carácter general y alcance regional ( $\sin$ perjuicio de planes de menor entidad), en el que se encuentran CastillaLa Mancha, la Comunidad Valenciana y Murcia.

B) Un segundo grupo que han previsto en sus respectivas leyes sobre turismo planes turísticos que presentan connotaciones más bien de carácter económico o estratégico de tipo sectorial pero, en todo caso, con escasa repercu-

\footnotetext{
${ }^{11}$ Se ha tomado como referencia el esquema propuesto por M. M. RAZQUIN LIZARRAGA, que distingue tres modelos autonómicos de planificación turística de ordenación (Modelo de planificación turística en plena inserción con la planificación territorial; modelo de planificación turística en coordinación con la planificación territorial; y modelo de planificación turística, independiente de la planificación territorial, de carácter estratégico y/ o económico), al margen de un grupo de regulaciones autonómicas en las que no se contemplan instrumentos de planificación turística; en Planificación turística y planificación territorial: la necesidad de una convergencia, en ob. col. Ordenación y gestión del territorio turístico, (Dir. D. Blanquer Criado), Valencia, 2002, págs. 118 ss.
} 
sión en los aspectos territoriales. En consecuencia, no se ha establecido claramente una relación de los mismos con los instrumentos de ordenación territorial. Se incluyen aquí los casos de Castilla y León, Cantabria, Extremadura, La Rioja, Madrid y Navarra.

C) Un tercer grupo de Comunidades Autónomas que contemplan una planificación turística coordinada con la planificación territorial. En estos casos, normalmente, las propias leyes turísticas prevén la formulación de Planes, valiéndose de alguno de los instrumentos de ordenación territorial previstos en las leyes de ordenación territorial autonómicas; concretamente a través de la figura de los Planes Territoriales Sectoriales. Se consideran incluidas en este grupo las Comunidades Autónomas del País Vasco, Asturias, Cataluña, Aragón y, con ciertas diferencias, Andalucía y Galicia.

D) Por último, debido a la presión, especialmente intensa, que el turismo produce sobre el territorio de los dos archipiélagos, en Canarias y Baleares se ha llevado a cabo una inserción muy estrecha entre la planificación turística y la planificación territorial.

De la experiencia de estas dos últimas Comunidades se va a tratar con detenimiento a lo largo de estas Jornadas, por lo que no entramos en ello en este momento. Interesa, sin embargo, aterrizar describiendo la situación que al respecto se vive en nuestra Comunidad.

\section{Especial referencia a la situación de Andalucía}

\section{a. El Plan General deTurismo}

La Exposición de Motivos de la Ley 12/ 1999, de 15 de diciembre, de Turismo de Andalucía, partiendo del reconocimiento de que el turismo constituye una de las actividades económicas con mayor incidencia territorial en la Comunidad y que, por tanto, ha de jugar un papel fundamental en la construcción del modelo territorial de la misma, destaca la necesidad de que «su planificación debe hacerse en plena coherencia con la planificación territorial, ya definida en las Bases y Estrategias del Plan de Ordenación del Territorio de Andalucía».

Para ello la Ley turística dejó prevista la formulación de un Plan General deT urismo, recientemente aprobado por medio del Decreto 340/ 2003, de 9 de diciembre (BOJA de 15 de enero de 2004), que se configura legalmente ( art. 15) como el principal instrumento de planificación sectorial turística, tenien- 
do por objeto la definición del modelo y de la estrategia de desarrollo turístico de la Comunidad. Por su parte, la propia Ley de Turismo califica a dicho Plan como Plan con Incidencia en la Ordenación del Territorio, que es uno de los instrumentos de ordenación previstos en la Ley de O rdenación del Territorio de Andalucía, lo que implica su subordinación a las determinaciones de los dos instrumentos principales de planificación territorial previstos en dicha Ley; esto es, el Plan de Ordenación del Territorio de Andalucía y las de los Planes de Ordenación del Territorio de ámbito subregional que les pudieran afectar.

La calificación formal del Plan General de Turismo como Plan con Incidencia en la Ordenación del Territorio asegura, a la vez, una orientación específicamente territorial de los contenidos del Plan, como así es visible en el texto finalmente aprobado en el que destacan las consideraciones sobre la relación entre turismo y territorio realizadas en el capítulo VI de la parte del Plan dedicada al Diagn óstico titulado "Territorio y sostenibilidad", aśi como en las Estrategias del mismo, entre las que figuran las de "Ordenación de los recursos y reequilibrio territorial" y la de "sostenibilidad", traduciéndose en acciones concretas en las correspondientes Fichas de medidas contenidas en dicho documento (Programa SENDA; Programa de grandes ciudades; Pacto por la defensa del litoral andaluz; Programa de actuaciones en playas; Programa de señalización turística; Sistema de indicadores ambientales del turismo; etc).

b. Zonas de Preferente Actuación Turística y Programas de Recualificación de Destinos

El artículo 15.2 de la Ley de Turismo de Andalucía también prevé que el Plan General de Turismo puede directamente establecer Zonas de Preferente Actuación Turística así como Programas de Recualificación de Destinos, que son dos interesantes instrumentos establecidos en dicha Ley.

Efectivamente, la declaración de las primeras conlleva la elaboración de un Plan de Actuación Turística Integrada que se presenta como una herramienta dirigida a impulsar el desarrollo ordenado y sostenible de zonas turísticas que presentan un potencial turístico, a través de la articulación de medidas de ordenación territorial, de la preservación y potenciación de los recursos turísticos, del fomento de la prestación de servicios turísticos de calidad, y de la mejora de las dotaciones de infraestructuras y equipamientos.

Por su parte los Programas de Recualificación de Destinos pueden suponer un mecanismo apropiado para impulsar la rehabilitación progresiva de 
aquellas zonas turísticas con problemas de degradación medioambiental o saturación, a través de la articulación de medidas restrictivas y de la mejora de las dotaciones de infraestructuras y equipamientos, siendo su objetivo la recuperación ambiental y la recualificación general del espacio y de los recursos turísticos de lo que ha de resultar una mejora de la calidad del destino turístico considerado en su conjunto.

El Plan General de Turismo, no obstante, ha prescindido de declarar directamente Zonas preferentes o Programas de recualificación para espacios determinados, limitándose a recoger en sendas fichas de medidas la previsión genérica de puesta en marcha de este tipo de planes; lo que resulta posible a iniciativa de los municipios afectados o de la Consejería de Turismo. Ello, sin embargo, se va a ver a corto plazo dificultado por la ralentización sufrida en el desarrollo reglamentario de estas dos figuras que venía siendo objeto de elaboración en el seno de la Consejería de Turismo y Deporte.

En fin, de esta forma se traba la conexión entre la planificación turística con la territorial en el ámbito de la acción pública de la Comunidad. No obstante, la incidencia territorial del principal instrumento de planificación turística (Plan General de Turismo) presenta en Andalucía un alcance más atenuado que en el caso de las Comunidades anteriormente examinadas (País Vasco, Aragón, Asturias y Cataluña), toda vez que la Ley de Ordenación del Territorio autonómica no reconoce a los Planes con Incidencia en la Ordenación del Territorio los mismos efectos jurídicos (arts. 20 a 24 de dicha Ley) que al Plan de Ordenación del Territorio de Andalucía ni a los Planes de Ordenación del Territorio de ámbito subregional, lo que se traduce, por ejemplo, en la falta de un reconocimiento expreso de la vinculatoriedad de los primeros en relación con el planeamiento urbanístico; verdadero talón de aquiles del Plan sectorial turístico.

\section{c. Planes de Ordenación del Territorio de ámbito subregional}

Sí se alcanzaría la plena aplicación de los efectos aludidos en el caso de que la Administración andaluza decidiera acudir a la formulación de un Plan de O rdenación del Territorio de ámbito subregional para la ordenación integral de una Zona de Preferente Actuación Turística, posibilidad expresamente prevista en el artículo 16.6 de la Ley de Turismo de Andalucía, en un nuevo intento por relacionar lo turístico con lo territorial, pero cuyo desarrollo reglamentario, como decíamos, no se ha ultimado todavía.

Ello no ha de impedirnos, sin embargo, resaltar la importancia otorgada a los aspectos turísticos en los cuatro Planes subregionales aprobados hasta el 
momento (los de la aglomeración urbana de Granada, Poniente de Almería, Sierra de Segura y el del ámbito de Doñana) y, asimismo, previsiblemente, en los numerosos Planes de este tipo cuya formulación ha sido ya acordada, especialmente en los de ámbito litoral (conviene destacar a estos efectos, como dato de actualidad, la reciente aprobación por parte de la Comisión de redacción del Plan subregional de la Bahía de Cádiz y la relevancia para el sector de los dos Decretos de 20 de enero de 2004, por los que se ha acordado la formulación de los Planes subregionales de la Costa del Sol O ccidental y del Litoral Oriental-Axarquía, ambos en la provincia de Málaga).

Tomando como ejemplo el Plan de Ordenación del Territorio del Poniente de la provincia de Almería (Decreto de 30 de julio de 2002), resulta constatable la atención prestada a los aspectos netamente turísticos y a los recursos turísticos en su normativa. Así, se establecen las directrices de ordenación y compatibilización de los distintos usos; se clasifican expresamente los suelos turísticos en las categorías de, suelos turísticos consolidados suelos turísticos previstos por el planeamiento y suelos turísticos propuestos por el propio Plan; se establecen unas determinaciones muy precisas sobre los suelos turísticos previstos y propuestos; se incluyen asimismo una serie de determinaciones para la protección y mejora del paisaje, etcétera; y todo ello vinculando al planeamiento municipal.

El reciente Plan de Ordenación del Territorio del ámbito de Doñana (Decreto 341/2003, de 9 de diciembre), desciende todavía más, si se quiere, en el grado de pormenorización, estableciendo, por ejemplo, determinaciones en relación con los índices de edificabilidad (que reduce) en determinados espacios destinados a uso turístico 0 , incluso, fijando directamente la tipología y el número de plazas turísticas que pueden ser permitidas según las distintas zonas o núcleos delimitados por el Plan.

\section{RELACIONES CON LA LEGISLACIÓN URBANÍSTICA}

Respecto a las relaciones con la legislación urbanística, serían muchos los asuntos a tratar pero, para no perdernos en la maraña, nos parece conveniente centrar nuestra atención únicamente en el par de cuestiones propuestas a continuación.

\section{Incidencia de la normativa urbanística sobre la ordenación de la urbaniza- ción turística}

a. La conveniencia de adoptar unos parámetros urbanísticos específicamente turísticos 
En primer lugar, debemos centrarnos en un asunto principal que guarda relación con la conveniencia de adoptar unos parámetros urbanísticos específicamente turísticos.

Efectivamente, tradicionalmente la urbanización turística se ha venido realizando en base a criterios y parámetros propios de la de carácter residencial ${ }^{12}$. Sin embargo, las características de la urbanización para uso turístico y las necesidades que la misma está llamada a satiffacer, ponen de manifiesto la conveniencia de introducir unas reglas específicas a través de la normativa urbanística, con el fin de cualificar estos espacios en razón de su funcionalidad, que no es otra que la de atender cumplidamente las necesidades de los usuarios turísticos. A ello puede contribuir, por ejemplo, la instauración de parámetros que doten de una mayor proporción de espacios públicoso de zonas ajardinadas en el sector objeto de ordenación, la implantación de una dotación suficiente de plazas de aparcamiento o la previsión de equipamientos complementarios relacionados con el ocio.

b. L os estándares u rbanísticos específicos para suelo tu rístico y los requisitos de infraestructura introducidos por la legislación canaria y el planeamiento insular balear

En algunas Comunidades Autónomas se han venido introduciendo medidas en la indicada dirección.

Así, en Canarias, la Ley de ordenación territorial y urbanística ${ }^{13}$, tras introducir la calificación urbanística de uso turístico diferente a la de uso residencial, fija directamente y con carácter general un estándar urbanístico específico para suelo turístico, indicativo de los niveles de equipamiento a nivel de sector, a observar obligatoriamente por el planeamiento urbanístico. Concretamente se dispone una reserva mínima de 50 metros cuadrados de suelo por cada 100 metros cuadrados de edificación, destinada a espacios libres públicos, dotaciones y equipamientos. Se establece, pues, una reserva de dotacio-

\footnotetext{
12 Vid. unas referencias a esta problemática en ROGER FERNÁNDEZ, G., El urbanismo y la ordenación y gestión del territorio turístico, en ob. col. Ordenación y gestión del territorio turístico, (Dir. D. Blanquer Criado), Valencia, 2002, pág. 69; y también en SO CÍAS CAMACHO, J. M., La incidencia del turismo en la ordenación del litoral (referencia especial al caso de las Islas Baleares), en ob. col. Régimen jurídico de los recursos turísticos, (ed. J. Tudela Aranda), Zaragoza, 1999, pág. 281.

${ }^{13}$ Decreto Legislativo 1/ 2000, de 8 de mayo, que aprueba el Texto Refundido de las Leyes de Ordenación del Territorio de Canarias y de Espacios Naturales de Canarias.
} 
nes locales, de aplicación específica a los sectores de suelo urbanizable calificados como de uso turístico.

El planeamiento insular balear recoge, igualmente, unas reservas dotacionales para las zonas turísticas. ${ }^{14}$

En ambas Comunidades se establecen también unas exigencias mínimas de infraestructura con las que deben de contar todos los desarrollos urbanísticos de carácter turístico, condicionando la concesión de autorizaciones a la acreditación de su cumplimiento. Aunque todos estos aspectos serán objeto de tratamiento más detenido en el transcurso de estas Jornadas, en Ias Ponencias correspondientes a la descripción de las experiencias de las I slas Baleares (a cargo del Prof. BLASCO ESTEVE) y de Canarias (a cargo del Prof. SUAY RINCÓN). ${ }^{15}$

c. La reserva para dotaciones y el índice máximo de edificabilidad en su elos con uso característico turístico en la Ley de Ordenación U rbanística de Andalucía

Por su parte, la Ley $7 / 2002$, de 17 de diciembre, de Ordenación U rbanística de Andalucía, en la misma línea que las examinadas, tiende a establecer mayores exigencias de calidad para las zonas con destino turístico respecto a las de uso residencial. De esta forma, se establece un estándar mínimo de reserva para dotaciones en suelo con uso característico turístico, que es sustancialmente superior al establecido para las mismas dotaciones en suelos con uso residencial, concretamente de entre un 25 y un $30 \%$ de la superficie del sector, debiendo destinar como mínimo un $20 \%$ a parques y jardines, y entre 1 a 1,5 plazas de aparcamiento público por cada 100 metros cuadrados de techo edificable.

Por otra parte, la misma Ley andaluza fija un índice máximo de edificabilidad de aplicación a los sectores con uso característico turístico de 0,3 metros cuadrados de techo por metro cuadrado de suelo que, asimismo, es sustancialmente más restrictivo que el correspondiente a los sectores de uso residencial ( $1 \mathrm{~m}^{2}$ de techo por $\mathrm{m}^{2}$ de suelo).

\footnotetext{
${ }^{14}$ Aspecto tratado en detalle en el importante trabajo de J. M. SO CíAS CAMACHO, La ordenación de las zonas turísticas litorales, Madrid, 2001, págs. 197 ss.

15 Profesores que ya se han ocupado previamente de las cuestiones señaladas en sendos trabajos: BLASCO ESTEVE, A., Planificación y gestión del territorio turístico de las I slas Baleares; y SU AY RINCÓN, J., T urismo y urbanismo: la ordenación turística del espacio. El caso de Canarias; ambos en ob. col. Ordenación y gestión del territorio turístico, (Dir. D. Blanquer Criado), Valencia, 2002.
} 
d. Previsiones específicas en relación con el uso turístico contenidas en otras leyes au ton ómicas de ordenación urbanística

Por último, cabe reseñar que al gunas otras leyes autonómicas sobre urbanismo contienen previsiones específicas en relación con las reservas para dotaciones en los suelos con uso turístico o para los municipios turísticos, aunque no son coincidentes en la línea de criterios adoptados, pudiendo distinguirse las siguientes situaciones:

A) La Ley de O rdenación Territorial y Régimen Urbanístico del Suelo de Cantabria establece la posibilidad de disponer un régimen urbanístico especial a los municipios turísticos, permitiéndoles superar la limitación de densidad máxima establecida con carácter general, pero imponiéndoles correlativamente, caso de adoptar esta opción, la el evación de los estándares dotacionales, tanto para sistemas generales como para sistemas locales.

B) Las leyes en materia de urbanismo de la Comunidad Valenciana, Castilla-La M ancha, Madrid y Navarra permiten, por el contrario, la posibilidad de minoración de determinados estándares dotacionales a sectores de carácter turístico; con diferencias de régimen en cada caso.

C) La Ley U rbanística de Aragón constituye un supuesto distinto a los anteriores, en cuanto que no prevé un incremento de los estándares ni la posibilidad de su minoración sino algo distinto: la posibilidad de cambiar el destino del módulo de reserva [ de $10 \mathrm{~m}^{2}$ ] para centros docentes y culturales, que podrá destinarse a incrementar las reservas de espacios verdes, deportivos, de recreo y para aparcamientos en los sectores de uso turístico.

Se comprueba, por tanto, cómo la legislación urbanística ha comenzado a tener en cuenta el fenómeno turístico dispensándole un tratamiento específico e incidiendo en la ordenación del turismo.

\section{Disposiciones de naturaleza urbanística establecidas desde la legislación sectorial turística}

Pero hay que señalar que esta incidencia legislativa se da también en la dirección inversa siendo así que, en algunos aspectos, desde la propia legislación sectorial turística se vienen estableciendo disposiciones de clara veste urbanística.

Especialmente sobresaliente en este sentido es la implantación de medidas dirigidas a mejorar la calidad de los establecimientos turísticos y, a la vez, a contener la densidad en las zonas turísticas. 


\section{a. La denominada ratio turística balear}

La legislación balear ha sido pionera en nuestro país en desplegar técnicas en la indicada dirección desde que, a través de los denominados Decretos Cladera I (1984) y II (1987) y posteriormente por la Ley de 1 de junio de1988 (todas ellas normas de ordenación de los establecimientos hoteleros), se estableció en dicha Comunidad la llamada ratio turística mínima de 60 metros cuadrados de suelo edificable por plaza turística que, finalmente es recogida por la Ley de Turismo de las Islas Baleares.

La ratio turística supone la exigencia al empresario de disponer de $60 \mathrm{~m}^{2}$ de parcela neta para la construcción de cada plaza de alojamiento turístico. Como ha apuntado BLASCO ESTEVE ${ }^{16}$, con ello se cumple una doble finalidad: a) por una parte se introduce un requisito de calidad dirigido a proporcionar una mayor amplitud en las instalaciones hoteleras; b) de otra, supone un instrumento que contribuye a la limitación de la densidad de población en las zonas de uso predominantemente turístico, por lo que no se trata únicamente de un parámetro turístico, sino también un parámetro de naturaleza urbanística ${ }^{17}$; pero de un parámetro dispuesto desde la normativa sectorial turística, queremos subrayar.

Posteriormente, los Planes I nsulares baleares han elevado frecuentemente los parámetros aludidos en relación con determinadas zonas turísticas.

b. El estándar mínimo de densidad en Canarias

En la senda de la legislación balear, en Canarias se ha establecido la misma técnica, bajo la denominación allí de estándar mínimo de densidad del suelo turístico ${ }^{18}$, fijado por la propia Ley de Ordenación del Turismo y concretado posteriormente por el relevante Decreto 10/ 2001, de 22 de enero, por el que se regulan los estándares turísticos, y también por los distintos Planes Insulares de Ordenación.

${ }^{16}$ BLASCO ESTEVE, A., Planificación y gestión del territorio turístico..., cit., págs. 241-243.

17 En este sentido BLASCO ESTEVE, A., Planificación y gestión del territorio turístico..., cit., pág. 243. Vid. también las consideraciones que hace al respecto SO CÍAS CAMACHO, J. M., La ordenación de las zonas turísticas..., cit., pág. 140.

${ }^{18}$ Vid. al respecto J. SU AY RINCÓ N, T urismo y urbanismo: la ordenación turística del espacio..., cit., págs. 302 y 314. 
c. La introducción de parámetros similares en Andalucía a través de la nueva re gulación dispensada a los establecimien tos hoteleros

Y en Andalucía, no podemos por menos que referirnos a la introducción de parámetros de naturaleza urbanística, de corte similar, a través de la nueva regulación dispensada a los establecimientos hoteleros.

Ello supone hablar de una novedad verdaderamente reciente, pues es en el Decreto 47/ 2004, de 10 de febrero, de Establecimientos Hoteleros, publicado el mismo día en que se dicta esta ponencia (BOJA de 2 de marzo de 2004), donde se introducen los parámetros a los que nos vamos a referir. Es de señalar que para su establecimiento ha sido necesario llevar a cabo, previamente, unas reformas puntuales de la Ley de Turismo - lo que se ha materializado por medio de la Ley de acompañamiento (Ley 18/2003, de 29 de diciembre, por la que se aprueban medidas fiscales y administrativas) -, que han permitido posteriormente al reglamento disponer el régimen sustantivo que podemos exponer sintéticamente a continuación:

1. Como es sabido, los establecimientos hoteleros tradicionalmente han debido ser clasificados obligatoriamente en grupos ( hoteles, hostales, pensiones, hoteles-apartamentos) y categorías (esto es, las consabidas estrellas). Según la nueva regulación, ahora también es obligatoria su clasificación en una modalidad.

2. Todo establecimiento hotelero en Andalucía ha de ser clasificado en adelante, pues, en una de estas cuatro modalidades: playa, ciudad, rural o carretera.

3. Para los establecimientos clasificados en la modalidad de playa ubicados en suelo urbano no consolidado, urbanizable ordenado o urbanizable sectorizado, se establece, una ratio de $110 \mathrm{~m}^{2}$ de parcela neta por unidad de alojamiento, cualquiera que sea su categoría (salvo en los de "Gran lujo" que se eleva a $150 \mathrm{~m}^{2}$ ). Ello implica la necesidad para el empresario de disponer de $110 \mathrm{~m}^{2}$ de parcela neta para la construcción de cada unidad de alojamiento; 0 , visto a contrario sensu, supone condicionar el número máximo de unidades de alojamiento que dicho empresario puede implantar en función de la superficie del solar de que disponga (por ejemplo, un máximo de 45 unidades si dispone de una parcela de $5.000 \mathrm{~m}^{2}$ ). O bsérvese que en la normativa andaluza, a diferencia de la de Baleares y Canarias, el segundo elemento de la proporción es la unidad de alojamiento y no la plaza turística (si estableciéramos una comparación equiparable la ratio aquí sería de $55 \mathrm{~m}^{2}$ por plaza turística, 
algo inferior a la de los archipiélagos). Asimismo se exige a los establecimientos de playa la existencia de piscina de unas determinadas dimensiones en función del número de plazas, de aparcamientos en proporción no menor de 1 plaza por cada dos unidades de alojamiento, y de zona ajardinada.

4. Los establecimientos de playa o rurales ubicados en suelo no urbanizable tienen establecido un requisito de unidad parcelaria mínima para su emplazamiento. Concretamente la parcela deberá tener una superficie resultante de multiplicar por 300 el número de unidades de alojamiento, con un mínimo, en todo caso, de $30.000 \mathrm{~m}^{2}$.

5. Por su parte, los establecimientos de carretera a emplazar en áreas o zonas de servicio deberán disponer de una parcela con una superficie resultante de multiplicar 150 por el número de unidades de alojamiento. Además la altura de la edificación no puede superar las dos plantas, además de la baja.

\section{RELACIONES CON LA LEGISLACIÓN DE PROTECCIÓN DEL MEDIO AMBIENTE}

\section{El contexto condicionante de la normativa medioambiental}

En último lugar trataremos de las relaciones de la ordenación del turismo con la legislación de protección del medio ambiente.

Con carácter previo parece necesario resaltar que la normativa medioambiental constituye un marco de referencia ineludible y condicionante para la planificación sectorial turística por cuanto buena parte de sus prescripciones resultan de obligado respeto por ésta. Se trata de disposiciones que se superponen y vinculan a la acción sectorial, que necesariamente ha de partir así del contexto prefijado por aquéllas.

\section{La normativa sobre espacios naturales protegidos}

En este sentido, una normativa que, frecuentemente, ha de resultar condicionante de la programación de nuevos desarrollos turísticos es la relativa a la conservación de los espacios naturales protegidos, tan numerosos hoy en nuestro país y que ocupan una gran extensión superficial. Se trata de espacios que resultan protegidos en virtud de su singular valor ecológico y especial representatividad ambiental por lo que, al mismo tiempo, presentan un potencial generador de corrientes turísticas, característica que implica su conside- 
ración como recursos turísticos conforme a la definición legal extendida de estos últimos.

Como ha notado MARTÍNEZ JIMÉNEZ, ni la Ley estatal de 4 de marzo de 1989, de Conservación de los Espacios Naturales y de la Flora y Fauna Silvestres, ni las leyes autonómicas sobre espacios naturales protegidos ( en nuestro caso la Ley de 18 de julio de 1989, de Inventario de Espacios Naturales de Andalucía) suelen contener disposiciones específicas sobre el desarrollo de actividades turísticas en dichos espacios, «remitiéndose, para la regulación de los usos a desarrollar en los mismos, a la planificación ecológica»19. Los instrumentos de dicha planificación ecológica son los Planes de Ordenación de los Recursos Naturales y los Planes Rectores de U so y Gestión. y Gestión

Los Planes de Ordenación de los Recursos Natu rales son unos instrumentos administrativos singulares, de carácter normativo, que tienen como objeto genérico el establecer el régimen de protección, la ordenación y la determinación de las limitaciones respecto a los usos y actividades en función de la conservación del espacio a proteger. Específicamente se prevé como uno de sus objetivos el de «formular los criterios orientadores de las políticas sectoriales y ordenadoras de las actividades económicas y sociales, públicas y privadas, para que sean compatibles con las exigencias [ de protección y conservación] señaladas» (art. 4. 3, e, Ley 4/ 1989, de 27 de marzo).

Una de las singularidades más notables de los Planes de O rdenación de los Recursos Naturales (PORN) , que conviene resaltar, consiste en que sus determinaciones se imponen a las de otras figuras de planeamiento. El artículo 5 de la Ley 4/ 1989 -que tiene carácter básico- establece a estos efectos que los citados Planes serán obligatorios y ejecutivos en las materias reguladas por la Ley, constituyendo sus disposiciones un límite para cualesquiera otros instrumentos de ordenación territorial o física, debiendo adaptarse a éstos cuando resulten contradictorias con sus contenidos. Mientras dicha adaptación no tenga lugar se aplicarán en todo caso las determinaciones de los Planes de Or-

19 MARTÍNEZ JIMÉNEZ, E., Los instrumentos de ordenación de los usos turísticos en los espacios sometidos a un régimen especial de protección ambiental, en ob. col. V Congreso de Turismo Universidad y Empresa: La calidad integral del turismo, (Dir. D. Blanquer), Valencia, 2003, pág. 141. 
denación de los Recursos Naturales que prevalecerán sobre los instrumentos de ordenación territorial o física existentes.

Por su parte los Planes R ectores de U so y G estión de los Parques establecen las directrices, régimen de usos y la ordenación general de cada espacio declarado como tal. Conforme al artículo 19.2 de la Ley 4/ 1989, estos Planes prevalecerán sobre el planeamiento urbanístico, debiendo revisarse este último de oficio por los órganos competentes cuando sus determinaciones resulten incompatibles con las establecidas por aquéllos.

Frecuentemente los Planes aludidos contienen determinaciones bastante precisas acerca de extremos tales como las características de las infraestructuras para la atención del público, el emplazamiento y la tipología de las construcciones relacionadas con la actividad de hostelería, o las modalidades de alojamiento permitidas.

\section{b. Un ejemplo reciente el PORN del Frente Litoral Algeciras-T arifa}

Tomando como ejemplo el Plan de Ordenación de los Recursos Naturales del Frente Litoral Algeciras-T arifa, aprobado por Decreto 308/ 2002, de 23 de diciembre, que afecta a una amplia zona estratégica del litoral andaluz, puede comprobarse cómo en el mismo se reflejan una serie de estrategias y determinaciones que afectan de lleno a las posibilidades de desarrollo de actividades turísticas y de implantación de instalaciones en el espacio afectado por el mismo.

En este sentido, entre los objetivos referidos al modelo turístico se señalan criterios, dirigidos al planeamiento, tales como: que los establecimientos turísticos deben ubicarse, preferentemente, en edificaciones existentes objeto de rehabilitación y bajo la condición de equipamiento hotelero; o que las características constructivas de las edificaciones vinculadas a actividades turísticas deben integrarse en el entorno paisajístico y acomodarse a la arquitectura tradicional de la zona. Por otra parte se indica que la demanda de suelo para usos turísticos ha de atenderse preferentemente en los núcleos urbanos consolidados o en las áreas contiguas.

Ya entre las disposiciones normativas se establece la determinación de que los establecimientos turísticos de nueva planta deberán guardar una distancia mínima de 200 metros con el límite del dominio público marítimo-terrestre y también una distancia mínima de 500 metros respecto a otros equipamientos turísticos; así como una fuerte limitación de construcción o am- 
pliación de viviendas destinadas a segunda residencia en todo el ámbito de aplicación del Plan.

EI PORN que comentamos lleva a cabo una zonificación del territorio en tres tipos de zonas [ Zonas de Reserva ( Grado A), Zonas de regulación especial ( Grado B) y Zonas de regulación común ( Grado $C$ ) ], subdivididas a su vez, las dos primeras, en varias categorías. En las normas particulares sobre usos y actividades incompatibles relativas a cada una de las zonas así delimitadas se ponen de manifiesto las fuertes restricciones -que en ocasiones son rotundas prohibiciones- a que quedan sometidas cualesquiera actividades edificatorias en las dos primeras tipologías de Zonas señaladas, lo que, obviamente, condiciona, o simplemente elimina, las posibilidades de implantación de futuros proyectos de desarrollos turísticos en establecimientos alojativos.

c. La normativa reguladora de determinadas actividades turísticas en cuan to éstas se desenvuelven en los espacios naturales

También se viene observando una interrelación mutua entre la normativa medioambiental y la reguladora de determinadas actividades turísticas en cuanto éstas se desenvuelven en los espacios naturales. Así se hace visible en el artículo 23 de la reciente Ley andaluza 8/ 2003, de 28 de octubre, de la Flora y Fauna Silvestres, que se refiere a las condiciones de práctica de las actividades deportivas, de ocio y turismo activo que se desenvuelvan en el medio natural. Aspecto que, en lo referente al turismo activo, ha sido objeto de una regulación pormenorizada por medio de la Orden conjunta de las Consejerías de Turismo y Deporte y de Medio Ambiente de 20 de marzo de 2003, que establece las obligaciones y condiciones medioambientales para la práctica de las actividades integrantes del turismo activo; dictada en desarrollo del Decreto andaluz 20/ 2002, de 29 de enero, de Turismo en el Medio Rural y Turismo Activo.

\section{La sujeción a evaluación de impacto ambiental de determinados proyectos relativos a actuaciones turísticas}

En otras ocasiones es el propio proyecto turístico el que queda sujeto a la principal técnica de prevención de impactos dañinos al entorno natural: la evaluación de impacto ambiental, así como, en su caso, a la normativa sobre actividades clasificadas. El Real Decreto Legislativo 1302/ 1986, de 28 de junio de Evaluación del Impacto Ambiental, tras su modificación por Ley 6/2001, de 8 de mayo, somete a dicho requisito a determinados proyectos relativos a actuaciones turísticas a desarrollar en zonas especialmente sensibles 0 , no 
siéndolos, cuando así lo decida el órgano ambiental en cada caso. Es el caso, según las circunstancias, de los proyectos de urbanizaciones y complejos hoteleros fuera de las zonas urbanas y construcciones asociadas, incluida la construcción de centros comerciales y de aparcamientos; de las pistas de esquí, remontes, tel eféricos y construcciones asociadas; de los parques temáticos; campings, etc.

En el marco de la norma estatal reseñada -que tiene carácter de legislación básica en materia de protección del medio ambiente- hay que atender a la abundante normativa autonómica de carácter ambiental que, frecuentemente, supedita la instalación de ciertas infraestructuras turísticas a la evaluación de impacto ambiental o a alguna figura similar, como ocurre en Andalucía con algunas de las actuaciones incluidas en los Anexos de la Ley 7/ 1994, de Protección Ambiental, que integra la regulación de la técnica de evaluación de impacto ambiental y la relativa a la autorización de actividades clasificadas ( por ejemplo, la sujeción a informe ambiental de complejos deportivos y recreativos, campos de golf y campings en suelo no urbanizable).

En algunos casos incluso se han establecido cauces de conexión entre la política ambiental y la turística, disponiendo directamente en las propias leyes de turismo autonómicas la necesidad de evaluación de las repercusiones ambientales de determinados proyectos turísticos, como ha notado MARTÍNEZ JIMÉNEZ. 20

\section{La sujeción de las instalaciones turísticas a otras normativas en materia de protección medioambiental}

Finalmente, es obvio que las instalaciones turísticas quedarán sometidas, según los casos, a las normas vigentes en materia de protección contra ruidos, protección atmosférica, sobre residuos y demás normativas generales en materia de protección medioambiental. De ello constituyen buen exponente las disposiciones introducidas en el reciente Decreto de Establecimientos Hoteleros en Andalucía, anteriormente aludido, relativas a insonorización de los establecimientos, tratamiento y eliminación de residuos, tratamiento y evacuación de aguas residuales, reutilización de aguas grises, regeneradas y pluviales, o requisitos de eficiencia energética; con cuya nueva referencia podemos dar por terminada esta intervención.

20 MARTÍNEZ JIMÉNEZ, E., Los instrumentos de ordenación de los usos turísticos..., cit., págs. 139-140. Dicha autora cita ejemplos extraídos de las Leyes turísticas de Canarias, Extremadura y Asturias. 